\title{
Eventos externos e internos da infecção de larvas e ninfas de Rhipicephalus sanguineus por Metarhizium anisopliae
}

[External and internal events of Rhipicephalus sanguineus larvae and nymphs infection by Metarhizium anisopliae]

\author{
M.V. Garcia ${ }^{1}$, A.C. Monteiro ${ }^{2 *}$, M.P.J. Szabó ${ }^{3}$, N. Prette $^{1}$ \\ ${ }^{1}$ Aluno de pós-graduação - FCAV-UNESP - Jaboticabal, SP \\ ${ }^{2}$ Faculdade de Ciências Agrárias e Veterinárias - UNESP \\ Via de Acesso Prof. Paulo Donato Castellane, s/n \\ 14884-900 - Jaboticabal, SP \\ ${ }^{3}$ Universidade Federal de Uberlândia - Uberlândia, MG
}

\begin{abstract}
RESUMO
Examinaram-se a adesão, a germinação, a penetração e a colonização de larvas e ninfas de Rhipicephalus sanguineus por Metarhizium anisopliae, assim como as lesões infringidas pelo fungo nas respectivas fases do ciclo de vida do ácaro. Realizaram-se infecções experimentais em 11 grupos contendo 250 larvas e 11 grupos contendo 75 ninfas de $R$. sanguineus, por meio de banho, durante três minutos sob agitação manual, em suspensão contendo $10^{8}$ conídios/ml do fungo. Nos grupos-controles, o banho foi realizado usando o veículo da suspensão. Larvas e ninfas foram processadas para um estudo histopatológico e de microscopia eletrônica de varredura nos seguintes tempos após a infecção: uma e 18 horas, e um, dois, três, quatro, cinco, seis, sete, nove e 11 dias. A germinação dos conídios ocorreu em até 18 horas pósinoculação, e o fungo penetrou nas larvas e ninfas através do tegumento, dois e três dias após a infecção, respectivamente. Após penetração, o fungo invadiu o corpo das larvas e ninfas, promovendo uma colonização difusa, sem preferência aparente por tecidos específicos. Lesões significativas não foram observadas. A morte das larvas e ninfas ocorreu no terceiro e quarto dias pós-infecção, e a esporulação do patógeno sobre o cadáver foi iniciada no sexto dia pós-infecção.
\end{abstract}

Palavras-chave: cão, carrapato, controle biológico, controle microbiano, fungo entomopatogênico

\begin{abstract}
The adhesion, germination and colonization of Rhipicephalus sanguineus larvae and nymphs by Metarhizium anisopliae as well as the lesions caused by the fungus were studied. For this purpose, 11 groups of 250 larvae each and 11 groups of 75 nymphs each were bathed during 3 minutes under manual shaking in a $10^{8}$ conidia/ml suspension. Corresponding control groups were bathed only in the suspension vehicle. Ticks were also submitted to both conventional microscopy and scanning eletronmicrocopy analyses at several post-infection periods (1 and 18 hours and 1, 2, 3, 4, 5, 6, 7, 9, and 11 days). Conidial germination occurred in less than 18 hours post-inoculation and the fungus penetration through the tegument into the larvae and nymphs in, respectively, two and three days postinfection. Following penetration, the fungus invaded the body of the ticks and colonized it diffusely without a noticeable predilection for tissue, but no apparent lesions were observed. Death of larvae and nymphs occurred on the $3^{\text {rd }}$ and $4^{\text {th }}$ post-infection days and pathogen sporulation over the dead tick began on the $6^{\text {th }}$ post-infection day.
\end{abstract}

Keywords:dog, tick, biological control, microbial control, entomopathogenic fungus

Recebido em 29 de agosto de 2007

Aceito em 19 de maio de 2008

*Autor para correspondência (corresponding author)

E-mail: montecar@fcav.unesp.br 


\section{INTRODUÇ̃̃O}

Originário da região Afrotropical, Rhipicephalus sanguineus (Latreille, 1806), um carrapato cosmopolita, é provavelmente a espécie de maior disseminação mundial na atualidade (Pegram et al., 1987). Foi introduzido no Brasil possivelmente a partir do século XVI, com a chegada dos colonizadores europeus e seus animais domésticos (Labruna e Pereira, 2001) e representa a única espécie do gênero Rhipicephalus no país (Aragão e Fonseca, 1961), pois, apesar de sua ampla distribuição, todos os espécimens coletados de cinco regiões foram identificados como R. sanguineus (Ribeiro et al., 1996). Sua descrição tem sido freqüentemente associada à presença do hospedeiro natural que é o cão (Ribeiro et al., 1997; Szabó et al., 2001), estando adaptado a cães de domicílios em cidades.

Compostos químicos sintéticos (acaricidas) são comumente utilizados no controle desses ectoparasitos. No entanto, o desenvolvimento de resistência pelo carrapato a alguns princípios ativos utilizados para formulações de produtos (Miller et al., 2001) tende a reduzir sua eficiência no controle do ácaro. Uma das alternativas aos acaricidas sintéticos é o controle biológico, especialmente com fungos, que tem se mostrado uma técnica eficaz e promissora.

Alguns autores investigaram a ação de fungos no controle de $R$. sanguineus, mas a maioria dos trabalhos avaliou a patogenicidade de diferentes espécies de fungos (Bittencourt et al., 1997; Samish et al., 2001) ou o efeito de diversas concentrações de conídios nas várias fases do ciclo de vida do ixodídeo (Barbosa et al., 1997; Monteiro et al., 1998). Poucos estudos foram conduzidos com o objetivo de conhecer os vários aspectos envolvidos no mecanismo da infecção de carrapatos por fungos.

Bittencourt et al. (1999) mostraram, por meio de microscopia eletrônica de varredura, a adesão, germinação e formação do apressório, confirmando a hipótese de que Metarhizium anisopliae penetra em Boophilus microplus pela cutícula. Arruda et al. (2005) descreveram as alterações morfológicas ocorridas durante a penetração de B. microplus por $M$. anisopliae, referindo-se inclusive à secreção de enzimas hidrolíticas. A penetração e colonização de fêmeas ingurgitadas e ovos de $R$. sanguineus por $M$. anisopliae foram investigadas por Garcia et al. (2004) e Garcia et al. (2005), respectivamente. Contudo, o mecanismo de infecção das diferentes fases do ciclo de vida dos carrapatos por fungos precisa ainda ser melhor conhecido. Assim, este trabalho teve o objetivo de investigar a adesão, germinação, penetração e colonização de larvas e ninfas de $R$. sanguineus por $M$. anisopliae, assim como as lesões infringidas pelo fungo nas respectivas fases do ciclo de vida do ácaro.

\section{MATERIAL E MÉTODOS}

Utilizou-se o isolado E9 de $M$. anisopliae, obtido de Deois flavopicta (cigarrinha das pastagens), mantido em cultura estoque no laboratório de microbiologia do Departamento de Produção Vegetal da Faculdade de Ciências Agrárias e Veterinárias (FCAV) da Universidade Estadual Paulista (Unesp), Campus de Jaboticabal, SP. O isolado foi cultivado em placas de Petri contendo meio de batata, dextrose e ágar (BDA), acondicionadas em estufa a $27^{\circ} \mathrm{C}$, no escuro, por aproximadamente 12 dias.

Larvas e ninfas de $R$. sanguineus foram obtidas a partir de colônia mantida no laboratório de imunopatologia do Departamento de Patologia Animal da FCAV-Unesp. Os carrapatos da colônia foram alimentados em coelhos isentos de contato prévio com o ácaro e, durante a alimentação, ficaram contidos no interior de câmaras de plástico transparente (Bechara et al., 1989), fixadas no dorso depilado do animal com material atóxico. Para ecdise dos instares ingurgitados, assim como para simples manutenção, os ácaros foram mantidos em estufa a $28^{\circ} \mathrm{C}$ e umidade relativa do ar de $80 \%$.

As suspensões de conídios foram obtidas a partir das colônias jovens do fungo. Para proceder as infecções, utilizaram-se $20 \mathrm{ml}$ de uma suspensão preparada em solução de Tween $80^{\circledR}$ a $0,1 \%$ (v/v), contendo a concentração de $10^{8}$ conídios $/ \mathrm{ml}$.

As infecções experimentais foram realizadas utilizando-se 11 grupos compostos por 250 larvas e 11 grupos compostos por 75 ninfas de $R$. sanguineus, os quais foram banhados em $20 \mathrm{ml}$ da suspensão de conídios durante três minutos, 
sob agitação manual. Nos grupos-controle, o banho foi realizado usando o veículo da suspensão. Em seguida, o excesso de líquido foi retirado com papel de filtro e cada grupo de larvas ou ninfas foi acondicionado em tubo transparente etiquetado e mantido em estufa a $27^{\circ} \mathrm{C}$. Os tempos de colheita das larvas e ninfas infectadas e seus respectivos controles foram estabelecidos em uma e $18 \mathrm{~h}$, e um, dois, três, quatro, cinco, seis, sete, nove e 11 dias. Após colheita em cada tempo preestabelecido, as larvas $\mathrm{e}$ ninfas de $R$. sanguineus foram distribuídas em duas parcelas: uma destinada ao preparo histológico e outra para a microscopia eletrônica de varredura.

Os grupos destinados à análise histológica foram imersos em formol tamponado por $12-24 \mathrm{~h}$. O material fixado foi submetido à inclusão em parafina de acordo com técnicas rotineiras de histologia. Posteriormente, cortes longitudinais seriados foram realizados para obtenção de secções representativas dos tecidos do ácaro infectado e do controle. As secções foram coradas com os corantes hematoxilina-eosina, adequado para exame das alterações gerais dos tecidos do ácaro, e coloração Gomori Metanamine Stain, específica para detecção das estruturas fúngicas.

As larvas e ninfas destinadas à análise em microscópio eletrônico de varredura foram fixadas em glutaraldeído a 3\%, em tampão de fosfato de potássio a $0,05 \mathrm{M}$ e $\mathrm{pH} 7,4$ por $72 \mathrm{~h}$. Em seguida, foram lavadas em solução tampão pura, por seis vezes consecutivas, em intervalos de 20 minutos. Posteriormente, foram desidratadas em álcool etílico, secas em secador de ponto crítico em $\mathrm{CO}_{2}$, recobertas com partículas de ouro (35nm) e eletronmicrografadas em microscópio eletrônico de varredura JEOL JSM 5410, operando em 15 kV (Maia e Santos, 1997).

\section{RESULTADO E DISCUSSÃO}

A observação realizada no primeiro dia após a infecção mostrou que $78 \%$ das larvas examinadas apresentavam conídios aderidos de forma difusa em seu tegumento, e, 18h após a infecção, encontraram-se conídios germinados em $80 \%$ das larvas. Resultados semelhantes foram obtidos por Garcia et al. (2005), ao investigarem o mecanismo de infecção de $M$. anisopliae em ovos de $R$. sanguineus. A penetração do fungo e a colonização do hospedeiro foram detectadas em $67 \%$ das larvas já no segundo dia após a infecção, atingindo $100 \%$ no terceiro dia após a infecção. A extrusão do patógeno e a conidiogênese ocorreram em $47 \%$ das larvas no sexto dia pós-infecção, atingindo $87,5 \%$ no sétimo dia e a totalidade das larvas $(100 \%)$ no nono dia. Não foram observadas alterações nas larvas do tratamentocontrole, e aquelas que não foram processadas para análise permaneceram vivas até o final do experimento.

$\mathrm{Na}$ análise histológica das larvas do grupo-teste, a adesão conidial pôde ser observada pela presença de pequenos grumos negros, aderidos na região posterior do corpo da larva (Fig. 1A), mas no, grupo-controle, nada foi encontrado (Fig. 1B). Ao examinar as larvas colhidas $18 \mathrm{~h}$ após a infecção, observaram-se germinação dos conídios em várias regiões do corpo do hospedeiro (Fig. 1C) e colonização, de forma generalizada, já a partir do segundo dia após a infecção (Fig. 1D e 1E). Garcia et al. (2004) verificaram que a germinação e a penetração de $M$. anisopliae em fêmeas ingurgitadas de $R$. sanguineus ocorreram entre 18 e $48 \mathrm{~h}$ após a infecção do ácaro.

Lacey et al. (1988) estudaram o mecanismo de infecção de $M$. anisopliae em larvas de Culex quinquefasciatus e verificaram a morte do hospedeiro entre seis e $18 \mathrm{~h}$ após a ingestão de conídios. Ao estudarem as mudanças e alterações histológicas em larvas de C. quinquefasciatus causadas pelo fungo Langenidium gigantum, Bao et al. (1996) observaram alterações histológicas como aberturas nos tecidos da cabeça e do tórax e, conseqüentemente, a invasão dos músculos, intestinos e do resto do corpo do hospedeiro. As diferenças encontradas entre as observações deste estudo e as desses últimos autores sugerem que o mecanismo de infecção e colonização seja muito diversificado e pode variar conforme as espécies de fungos e de hospedeiros envolvidos.

As larvas infectadas começaram a morrer no terceiro dia após a infecção, atingindo mortalidade próxima a $70 \%$, e a extrusão do patógeno ocorreu a partir do sexto dia após a infecção, aumentando gradativamente até cobrir todo o cadáver do ácaro, com grande quantidade de esporos (Fig. 1F). Ao avaliarem a 
suscetibilidade de $R$. sanguineus ao fungo $M$. anisopliae, Samish et al. (2001) relataram mortalidade de larvas não alimentadas a partir do segundo e do terceiro dia após a infecção, e valor máximo no sétimo dia.

Nas larvas mortas, apesar de já colonizadas pelo fungo, não foram observadas alterações ou lesões
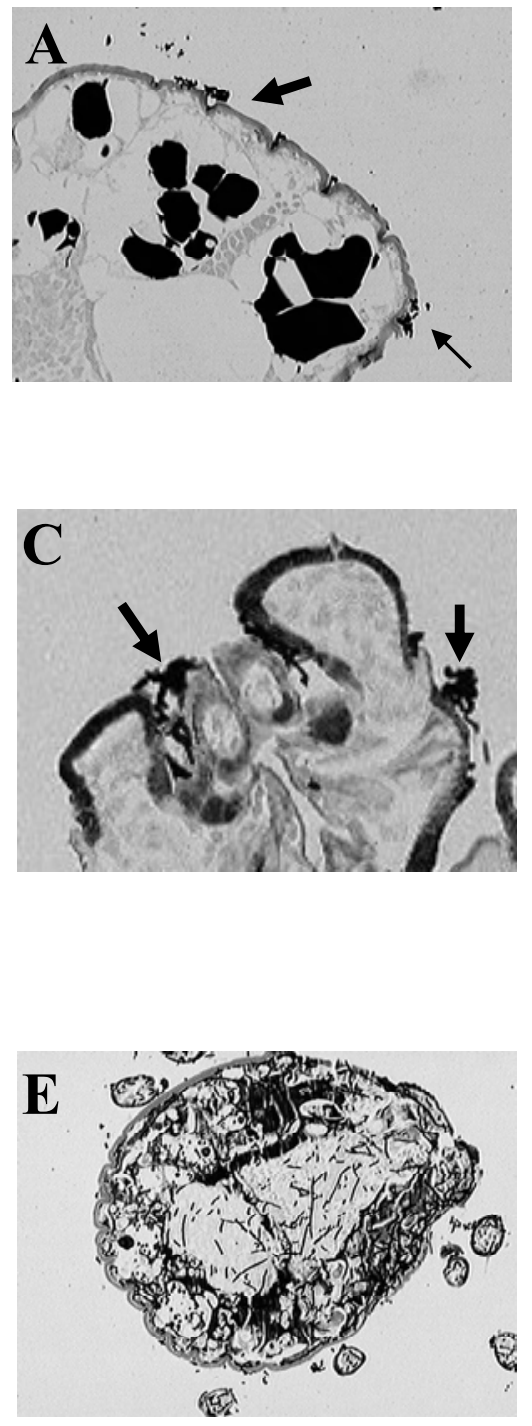

Figura 1. Larvas de Rhipicephalus sanguineus após a infecção experimental com suspensão conidial de Metarhizium anisopliae. A: conídios aderidos (seta) na região posterior do corpo da larva (GMS, objetiva 20x); B: controle de A (GMS, objetiva 20x); C: germinação dos conídios (setas) 18h após infecção, (GMS, objetiva 40x); D: densa colonização do corpo da larva (seta) três dias após a infecção (GMS, objetiva 20x); E: colonização do corpo da larva dois dias após a infecção (GMS, objetiva 10x); F: extrusão do patógeno (seta) seis dias após a infecção (GMS, objetiva 20x). 

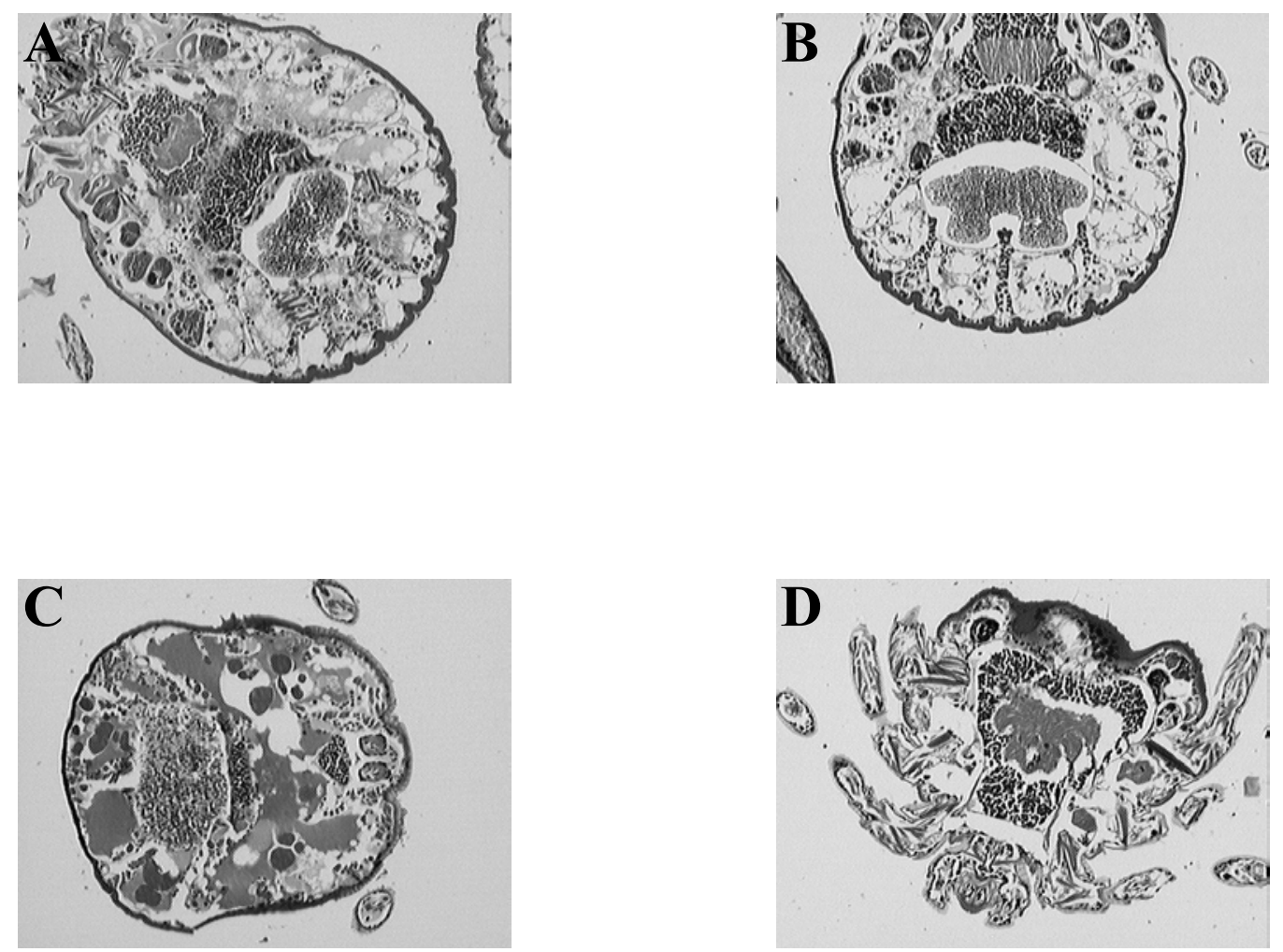

Figura 2. Larvas de Rhipicephalus sanguineus após a infecção experimental com suspensão conidial de Metarhizium anisopliae. A: larva do grupo-controle (HE, objetiva 20x); B: larva quatro dias após a infecção (HE, objetiva 20x); C: larva do grupo-controle (HE, objetiva 10x); D: larva três dias após a infecção (HE, objetiva 10x).

Eletronmicrografias realizadas $1 \mathrm{~h}$ após a infecção de larvas de $R$. sanguineus mostraram grande quantidade de conídios de $M$. anisopliae aderidos à cutícula. A distribuição apresentou-se relativamente uniforme em todas as partes do corpo do ácaro, sem preferência aparente por regiões ou sítios específicos (Fig. 3A). Este resultado difere do obtido por Vestergaard et al. (1999) que, ao estudarem a distribuição dos conídios no corpo de larvas de Frankliniella occidentalis infectadas por $M$. anisopliae, encontraram preferência por sítios específicos. Ademais, relataram germinação de conídios próxima da totalidade no prazo de um dia após a infecção.

Observações feitas $18 \mathrm{~h}$ após a infecção evidenciaram a germinação de conídios do patógeno sobre o corpo do hospedeiro (Fig. 3B) com grande quantidade de hifas sobre a cutícula externa do ácaro (Fig. 3C). Nesse tempo, formou-se também o apressório, estrutura que desempenha importante papel no processo de penetração do patógeno no hospedeiro (Fig. 3D). M. anisopliae não demonstrou invadir o corpo das larvas por aberturas, tais como o espiráculo, orifício anal e aparelho bucal. Fato semelhante foi relatado por Bittencourt et al. (1999) na infecção de $B$. microplus por este fungo. Mohamed et al. (1978) relataram que a penetração do fungo Nomuraea rileyi em larvas da lagarta Heliothis zea ocorreu no terceiro dia após a infecção. A extrusão e a conidiogênese do patógeno ocorreram a partir do sexto dia após a infecção do hospedeiro (Fig. 3E e 3F). 


\section{Garcia et al.}
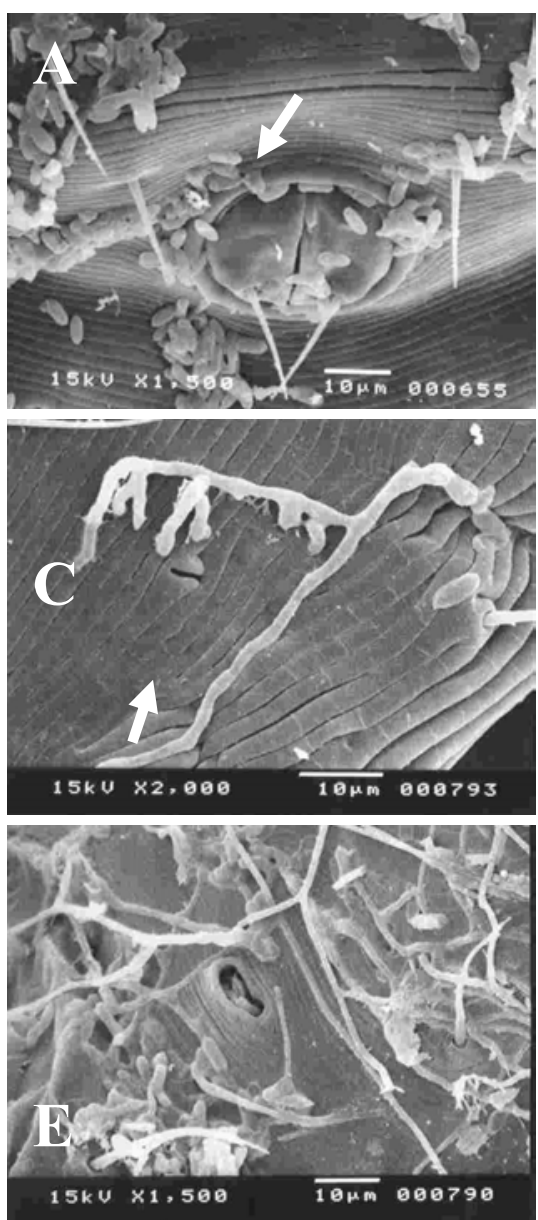
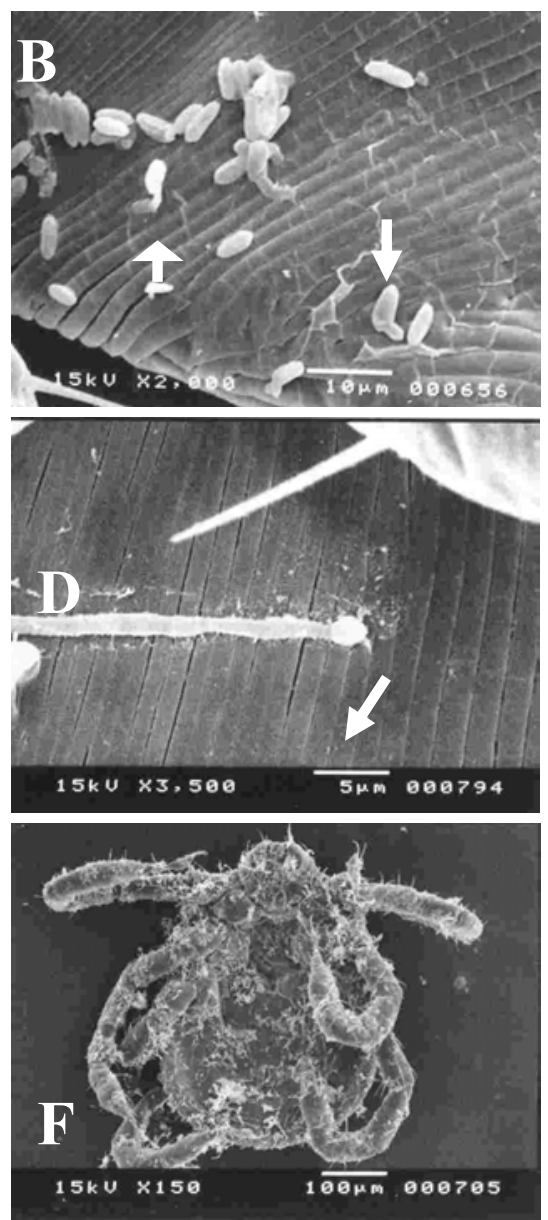

Figura 3. Eletronmicrografias de varredura de larvas de Rhipicephalus sanguineus após a infecção experimental com suspensão conidial de Metarhizium anisopliae. A: conídios aderidos ao orifício anal (seta) 1h após a infecção; B: germinação dos conídios (seta) 18h após a infecção; C: formação de corpos hifais (seta) sobre a cutícula externa; D: formação do apressório e penetração do fungo (seta) dois dias após a infecção; E: extrusão de M. anisopliae sobre o corpo da larva; F: larva seis dias após a infecção.

Foram analisadas apenas ninfas que se encontravam totalmente preservadas nas secções histológicas. Não foram observados conídios aderidos à cutícula do hospedeiro no período de $1 \mathrm{~h}$ após infecção, bem como sua germinação. Dificuldades inerentes ao processamento das amostras podem ter contribuído para este resultado, pois as ninfas são muito pequenas e de difícil manipulação. Além disso, ressalta-se o fato de ter sido utilizado menor número de indivíduos infectados (75), quando comparado com as larvas (250). Provavelmente, secções longitudinais de amostras que contenham maior quantidade de indivíduos possibilitem melhor observação da adesão e germinação dos conídios.
Observou-se, no entanto, que $67 \%$ das ninfas infectadas apresentavam o corpo densamente colonizado pelo fungo no terceiro dia após a infecção, atingindo $100 \%$ no quinto dia. O início da extrusão do patógeno foi observado no sexto dia após a infecção em $75 \%$ das ninfas infectadas, alcançando $100 \%$ no sétimo dia. Não se observaram alterações nas ninfas do tratamento-controle, e aquelas que não foram processadas para análise permaneceram vivas até o final do experimento.

$\mathrm{Na}$ análise histológica do grupo-teste, a adesão dos conídios não ficou evidente, bem como sua germinação (Fig. 4A). A colonização das ninfas infectadas foi detectada a partir do terceiro dia após a infecção (Fig. 4B e 4C). As ninfas 
infectadas começaram a morrer no quarto dia após a infecção, atingindo mortalidade próxima a $75 \%$. Este resultado é semelhante ao obtido por Samish et al. (2001), que relataram mortalidade de ninfas não alimentadas de $R$. sanguineus infectadas por $M$. anisopliae a partir do terceiro dia após a infecção, mortalidade esta que atingiu $92,2 \%$ no sétimo dia. A extrusão do patógeno foi iniciada a partir do sexto dia após a infecção, aumentando gradativamente até cobrir todo o
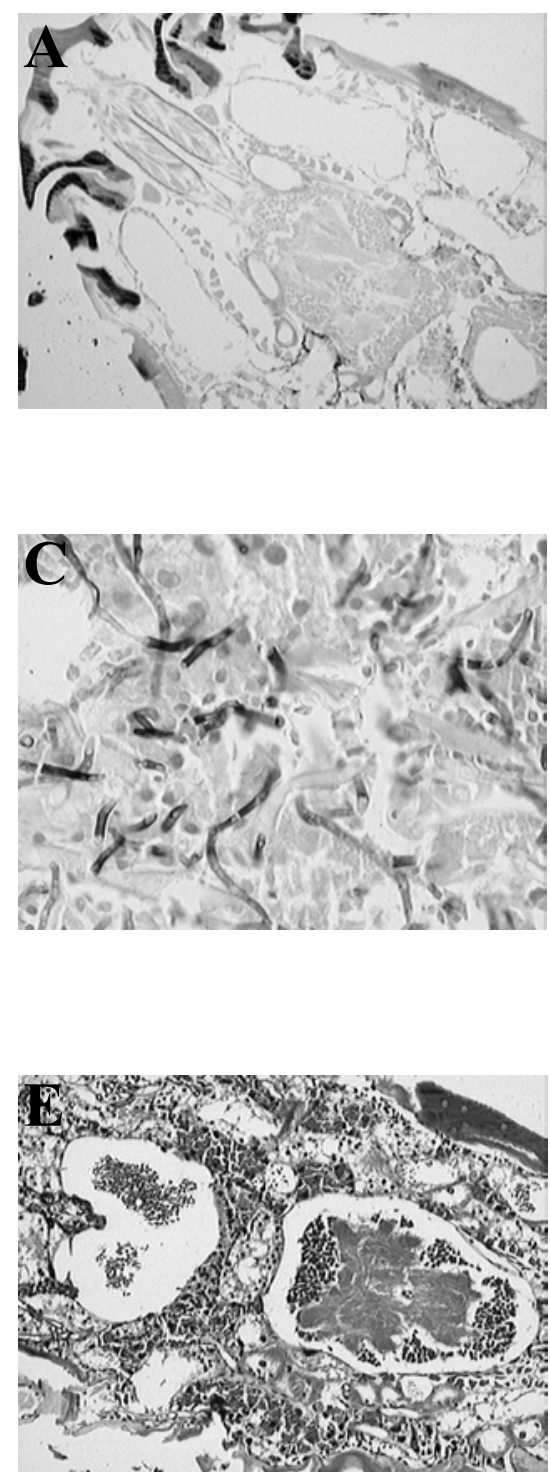

cadáver do ácaro, com a formação de grande quantidade de micélio (Fig. 4D). Ninfas do grupo-teste, apesar de mortas e já colonizadas pelo fungo, não mostraram alterações histológicas dignas de nota (Fig. 4E), em relação às ninfas do grupo-controle (Fig. 4F). Possivelmente, outras causas, como a ação de micotoxinas sobre o sistema nervoso do carrapato, foram responsáveis pela morte das ninfas.
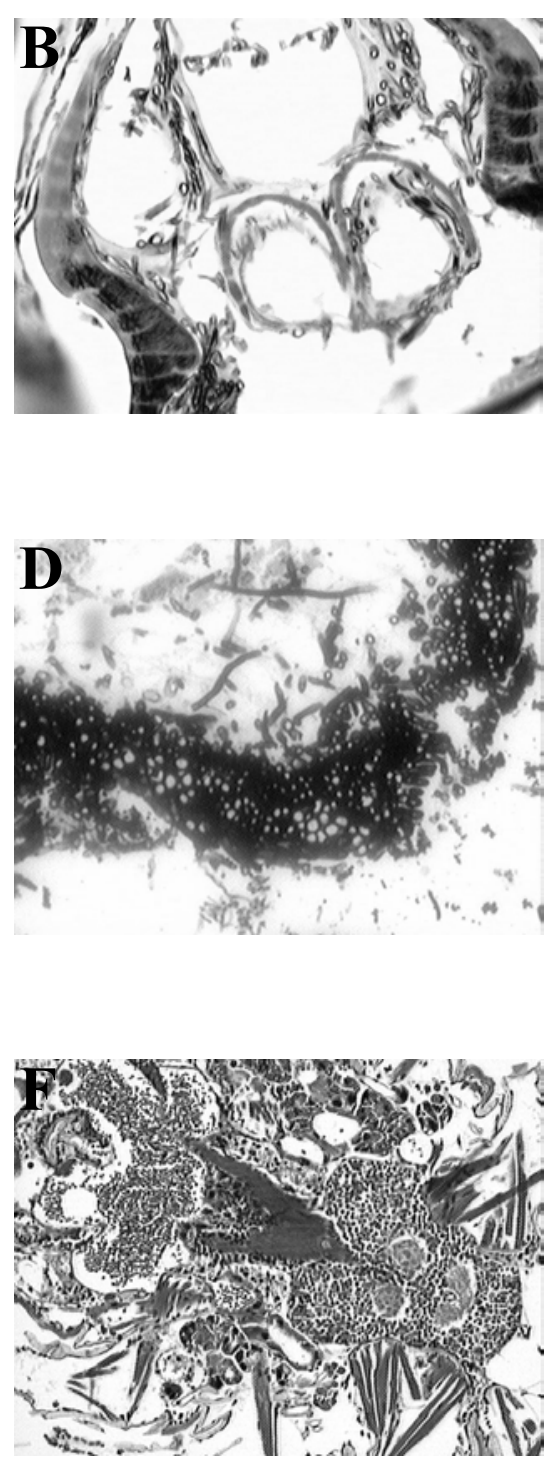

Figura 4. Fotomicrografias de ninfas de Rhipicephalus sanguineus após a infecção experimental com suspensão conidial de Metarhizium anisopliae. A: -ninfas 18h após a infecção (GMS, objetiva 20x); B e C: colonização generalizada em ninfas três dias após a infecção (GMS, objetiva 40x); D: extrusão e conidiogênese de $M$. anisopliae seis dias após a infecção (GMS, objetiva 40x); E: ninfa quatro dias após a infecção (HE, objetiva 40x); F: controle de E (HE, objetiva 20x). 
$\mathrm{Na}$ eletronmicrografia realizada na primeira hora após a infecção, ficou evidente a presença de grande quantidade de conídios de $M$. anisopliae aderidos à cutícula das ninfas, sem preferência aparente por regiões ou sítios específicos (Fig. 5A). A germinação de conídios sobre o corpo do hospedeiro foi observada $18 \mathrm{~h}$ após a infecção (Fig. 5B), com conseqüente formação de micélio (Fig. 5C, 5D e 5E). Tal resultado coincide com o obtido por Garcia et al. (2004) quando analisaram fêmeas ingurgitadas de $R$. sanguineus infectadas pelo fungo $M$. anisopliae.
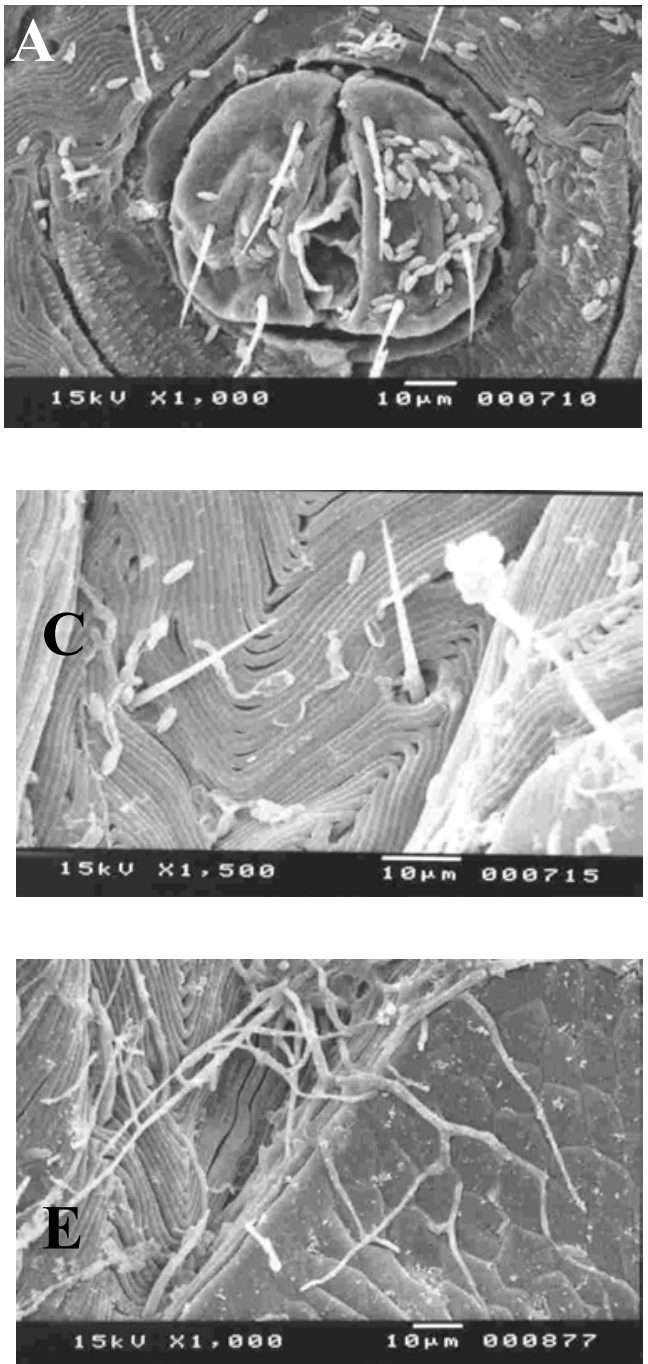

A formação do apressório bem como os locais ou sítios por onde ocorreu a penetração não foram observados nas eletronmicrografias. Conseqüentemente, não foi possível detectar preferência do patógeno pela penetração através da cutícula ou por aberturas naturais existentes no corpo das ninfas. Fato semelhante foi anteriormente observado por Bittencourt et al. (1999). A extrusão do fungo ficou evidente pela formação de grande quantidade de micélio e conidiogênese sobre o cadáver do hospedeiro (Fig. 5F).
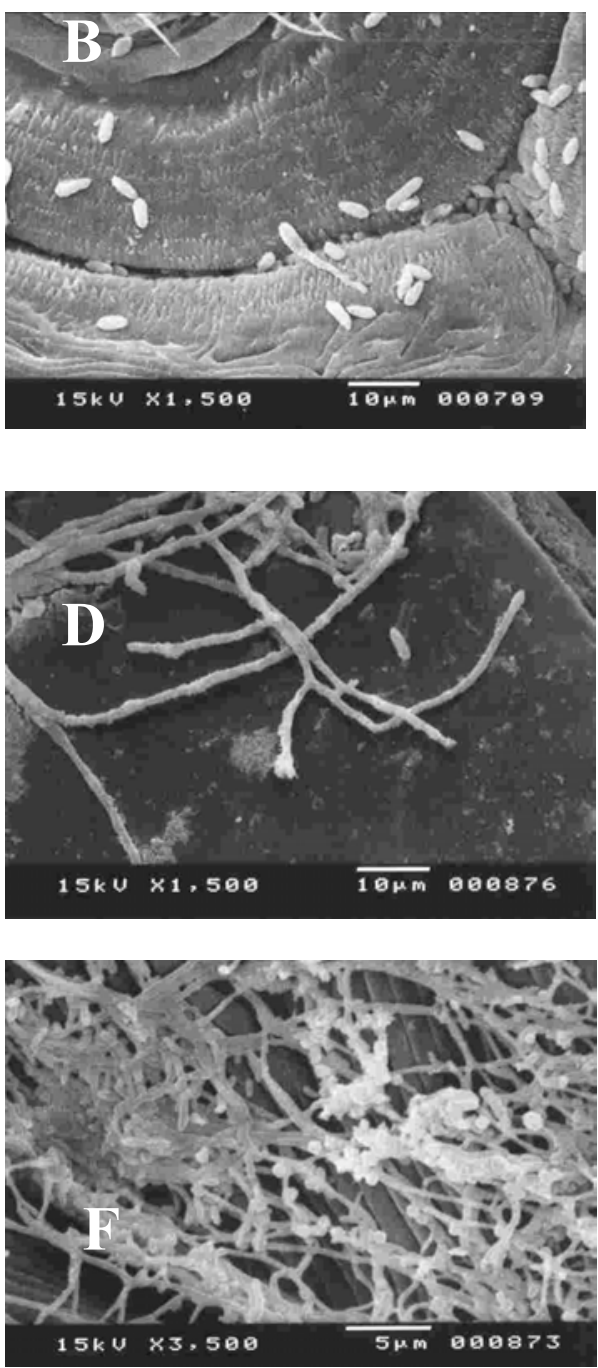

Figura 5. Eletronmicrografias de varredura de ninfas de Rhipicephalus sanguineus após a infecção experimental com suspensão conidial de Metarhizium anisopliae. A: Conídios aderidos à cutícula $1 \mathrm{~h}$ após a infecção; B: germinação do conídio $18 \mathrm{~h}$ após a infecção; C, D e E: formação de micélio na cutícula; F: extrusão e conidiogênese de $M$. anisopliae na superfície de $R$. sanguineus morto. 
Os resultados obtidos neste estudo mostraram que larvas e ninfas de $R$. sanguineus são susceptíveis à ação patogênica de $M$. anisopliae. A infecção inicia-se pela adesão dos conídios de forma generalizada sobre a cutícula, seguida de rápida germinação e penetração através desta, sem preferência por estruturas ou sítios específicos. O fungo coloniza intensivamente as estruturas internas de larvas e ninfas, sem causar lesões internas aparentes e sem preferência por tecidos ou órgãos específicos. Após a morte do hospedeiro, que acontece em poucos dias, ocorre a extrusão do patógeno sobre o cadáver das larvas ou ninfas, produzindo intenso crescimento micelial seguido de abundante formação de conídios.

\section{REFERÊNCIAS BIBLIOGRÁFICAS}

ARAGÃO, H.B.; FONSECA, F. Notas de Ixodologia. VII. Lista e chave para os representantes da fauna ixodológica brasileira. Mem. Inst. Oswaldo Cruz, v.59, p.115-130, 1961.

ARRUDA, W.; LUBECK, I.; SCHARANK, A. et al. Morfological alterations of Metarhizium anisopliae during penetration of Boophilus microplus tick. Exp. Appl. Acarol., v.37, p.231-244, 2005.

BAO, H.; SU, X.Q.; LANG, S.Y. et al.. Observation on the histological changes of mosquito larvae infected by Lagenidium giganteum. Chin. J. Parasitol. Parasit. Dis., v.14, p.303-306, 1996.

BARBOSA, J.V.; DAEMON, E.; BITTENCOURT, V.E.R.P. et al. Efeitos de dois isolados do fungo Beauveria bassiana (Bals.) Vuill., sobre a muda larval e sobrevivência de ninfas de Rhipicephalus sanguineus (Latreille, 1806) (Acari: Ixodiade). Rev. Bras. Parasitol. Vet., v.6, p.53-56, 1997.

BECHARA, G.H.; HELLER-HAUPT, A.; VARMA, M.G.R. et al. Development of immunity to Rhipicephalus appendiculatus in hamsters (Mesocricetus auratus). Imunobiology, v.4, p.176, 1989.

BITTENCOURT, V.R.E.P.; PERALVA, S.L.F.S.; SOUZA, E.J. et al. Efficacy of two isolates of Beauveria bassiana in engorged females of Boophilus microplus in the laboratory. Rev. Univ. Rural, Ser. Cien. Vida, v.19, p.65-71, 1997.

BITTENCOURT, V.R.E.P.; MASCARENHAS, A.G.; FACCINI, J.L.H. The penetration of the fungus Metarhizium anisopliae on Boophilus microplus in experimental conditions. Cien. Rural, v.29, p.351-354, 1999.

GARCIA, M.V.; MONTEIRO, A.C.; SZABÓ, M.P.J. Colonização e lesão em fêmeas ingurgitadas do carrapato Rhipicephalus sanguineus causadas pelo fungo Metarhizium anisopliae. Cien. Rural, v.34, p.1513-1518, 2004.
GARCIA, M.V.; MONTEIRO, A.C.; SZABÓ, M.P.J. et al. Mechanism of infection and colonization of Rhipicephalus sanguineus eggs by Metarhizium anisopliae as revealed by scanning eletron microscopy and histopathology. Braz. J. Microbiol., v.36, p.368-372, 2005.

LABRUNA, M.B.; PEREIRA, M.C. Carrapato em cães. Clin. Vet., v.6, p.24-32, 2001.

LACEY, A.C.; LACEY, L.A.; ROBERTS, D.R. Route of invasion and histopathology of Metarhizium anisopliae in Culex quinquefasciatus. J. Inverteb. Pathol., v.52, p.108-118, 1988.

MAIA, A.S.; SANTOS, J.M. A SEM technique for preparing biological control agents of nematodes in action. Acta Microsc., v.6, sérieB, p.550-551, 1997.

MILLER, R.J.; GUERRERO, F.; CARPENTER, L. et al. Characterization of acaricide resistence in Rhipiceplhalus sanguineus (Latreille) (Acari: Ixodidae) collected from the Corozal Army Veterinary Quarentine Center, Panama. J. Med. Entomol., v.2, p.298-302, 2001.

MOHAMED, A.K.A.; SIKOROWSKI, P.P.; BELL, J.V. Histopathology of Nomuraea rileyi in larvae of Heliothis zea and in vitro enzimatic activity. J. Inverteb. Pathol., v.31, p.345-352, 1978.

MONTEIRO, S.G.; BITTENCOURT, V.R.E.P.; DAEMON, E. et al. Ação dos fungos Beauveria bassiana e Metarhizium anisopliae em larvas do carrapato Rhipicephalus sanguineus. Cien. Rural, v.28, p.461-466, 1998.

PEGRAM, R.G.; CLIFFORD, C.M.; WALKER, J.B. et al. Clarification of de Rhipicephalus sanguineus group (Acari, Ixodoidea, Ixodidae). II. R. sanguineus (Latreille, 1806) and related species. Syst. Parasitol., v.10, p.27-44, 1987.

RIBEIRO, A. L.; FACCINI, J. L. H.; DAEMON, E. Estudo das variações morfológicas de Rhipicephalus sanguineus (Latreille, 1806) (Acari: Ixodidae) no Brasil. Rev. Univ. Rural, Ser. Cien. Vida, v.18, p. 25-33, 1996.

RIBEIRO, V.L.S.; WEBER, M.A.; FETZER, L.O. et al. Espécies de prevalência das infestações por carrapatos em cães de rua da cidade de Porto Alegre, RS, Brasil. Cien. Rural, v.27, p.285-289, 1997.

SAMISH, M.; GINDIN, G.; ALEKSSEV, E. et al. Pathogenicity of entomopathogenic fungi to different developmental stages of Rhipicephalus sanguineus (Acari: Ixodidae). J. Parasitol., v.38, p.1355-1359, 2001.

SZABÓ, M.P.J.; CUNHA, T.M.; PINTER, A. et al. Ticks (Acari: Ixodidae) associated with domestic dogs in Franca region, São Paulo, Brazil. Exp. Appl. Acarol., v.25, p.909916, 2001.

VESTERGAARD, S.; BUTT, T.M.; BRESCIANI, J. et al. Light and electron microscopy studies of the infection of the Western Flower Trips Frankliniella occidentalis (Thysanoptera: Thripidae) by the entomopathogenic fungus Metarhizium anisopliae. J. Inverteb. Pathol., v.73, p.25-33, 1999. 